\title{
Inhaltsverzeichnis
}

\section{zu Band I}

I. Abkürzungsverzeichnis . . . . . . . . . . . . . . . VII

II. Literaturverzeichnis . . . . . . . . . . . . . . . . . . . . . XIX

III. Ergänzungen und Berichtigungen . . . . . . . . . . . . . . XXIV

\section{Gesetzestexte}

(GT)

Inhaltsübersicht . . . . . . . . . . . . . . . . . . . . . . . . . 1

I. Die Grundbuchordnung (GT 1 ff.) . . . . . . . . . . . . . . . . 8

II. Ausführungsverordnung $(\boldsymbol{G T} \mathbf{4}) \quad \ldots \ldots \ldots$

III. Grundbuchverfügung (GT 5 ff.) $\ldots \ldots$. . . . . . . . . . . . . . . . . . . . 33

IV. Geschäftsordnung für die Grundbuchämter (GT 16) . . . . . . . . . . . 121

V. Ausfertigung der Hypotheken-, Grundschuld- und Rentenschuldbriefe $(G T 17,18) \ldots \ldots . . \ldots 133$

VI. Grundbuch und Kataster $(G T 19 f f)$. . . . . . . . . . . . . . . . . . 140

VII. Grundbuch und Wohnungseigentum (GT 32 ff.) . . . . . . . . . 164

VIII. Aktenordnung (GT 4Iff.) . . . . . . . . . . . . . . . . . 186

IX. Entlastungsverfügung $(G T$ 41) . . . . . . . . . . . . . . . . . . . 198

X. Verfahren der freiwilligen Gerichtsbarkeit (GT 45) . . . . . . . . . . 202

XI. Baden-Württemberg (GT 16 ff.) . . . . . . . . . . . . . . . . . . . 210

XII. 8owjetzone $(G T 56$ ff.) . . . . . . . . . . . . . . . . . . . . . . . 268

\section{Einleitung}

(E)

Inhaltsübersicht

I. Grundbuchordnung (E 1 f.)

Grundsätzliches . . . . . . . . . . . . . . . . . . . . 275

II. Hauptgrundsätze des Grundbuchrechts (E 9 f. $)$. . . . . . . . . . . . 287

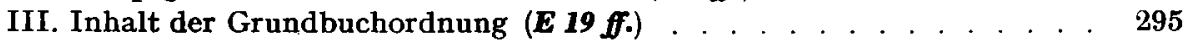

IV. Die Allgemeinen Verfügungen des früheren Reichsjustizministeriums

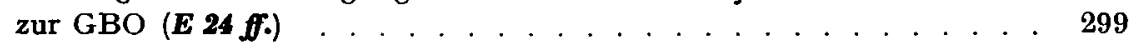

V. Immobilienrecht und Buchsystem, Abgrenzung des Begriffes des Grundbuchrechts $(E \mathbf{E} 27 \boldsymbol{f}$ ) . . . . . . . . . . . . . . . . . . . . 311

VI. Ergänzungsrecht zur Grundbuchordnung $(E \mathbf{E} 30$ ff. $) \ldots \ldots$

VII. Bodenschätzung und Liegenschaftskataster $(E \mathbf{E} \mathbf{f f})$. . . . . . . . . 316

VIII. Liegenschaftsrecht $(E \mathbf{E} \mathbf{f f})$. . . . . . . . . . . . . . . . . . . . . 351

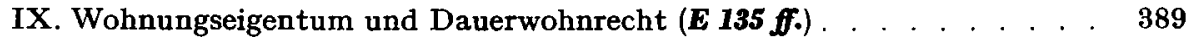

X. Landwirtschaftsrecht (E 154 ff. $)$. . . . . . . . . . . . . . . . . . . 399

XI. Bodenrecht, Wohnungs-, Bau- und Siedlungsrecht $(E \mathbf{E} 177 \mathrm{ff}$.$) . . . . . 415$ 
XII. Währungsumstellung und Lastenausgleich im Grundstücksrecht (E 218 ff. $) \quad 453$

XIII. Rückerstattung und Wiedergutmachung (E 228 ff.) . . . . . . . . . . 470

XIV. Preisrecht bei Grundstücken $(E \mathbf{E} 237 \boldsymbol{f}$.) . . . . . . . . . . . . . . . . 481

XV. Devisenrecht und Grundstücksverkehr (E 243 ff.) $\ldots \ldots . . . . . .493$

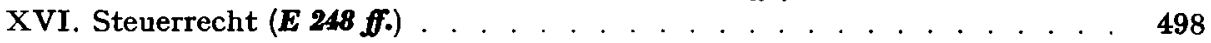

XVII. Notariatsrecht $(\boldsymbol{E} \mathbf{2 7 5} \boldsymbol{f}$. $)$. . . . . . . . . . . . . . . . . . . . . . . . . . . 534

XVIII. Der Rechtspfleger in Grundbuchsachen $(\boldsymbol{E} 278$ ff. $)$. . . . . . . . . . . 538

XIX. Der Rechtszustand im Familienrecht (E 282 ff.) . . . . . . . . . . . . 543

XX. Sowjetzonenrecht $(E \mathbf{E} 285 \boldsymbol{f f}$ ) . . . . . . . . . . . . . . . . . . . 548

\section{Kommentar zur Grundbuchordnung}

I. Abschnitt: Allgemeine Vorschriften . . . . . . . . . . . . . . . . . 551

Vorbemerkungen ..................... . . . 551

$\$ 1$ Grundbuchamt, Grundbuchbeamter . . . . . . . . . . . . . 552

$\S 2$ Grundbuch, Grundbuchbezirk, Grundstücksbezeichnung, Abschreibung 610

$\S 3$ Grundbuch, Grundbuchblatt, grundbuchfreie Grundstücke, Miteigentumsanteile . . . . . . . . . . . . . . . . . . . 684

Anhang I: Grundbuch und Grundbuchblatt . . . . . . . . . . . 722

Anhang II: Grundbuch und Wohnungseigentum nach dem Wohnungseigentumsgesetz . . . . . . . . . . . . . . . . . . . 917

\$4 Gemeinschaftliches Grundbuchblatt . . . . . . . . . . . . . . . . . 963

Anhang: Grundbuchrechtliche Behandlung der Heimstätte . . . . . . 981

$\S 5$ Vereinigung von Grundstücken . . . . . . . . . . . . . . . . . . . 996

Anhang: Änderungen an Flurstücken . . . . . . . . . . . . . 1023

§6 Zuschreibung . . . . . . . . . . . . . . . . . . . . . . . . . . . . 1027

$\S 7$ Belastung eines Grundstücksteils . . . . . . . . . . . . . . . . . . . 1040

$\S 8$ Erbbaurecht . . . . . . . . . . . . . . . . . . . . . . . . . . . . 1065

$\S 9$ Subjektiv-dingliche Rechte . . . . . . . . . . . . . . . . . . . . . . . 1087

$\S 10$ Aufbewahrung von Urkunden . . . . . . . . . . . . . . . . . . . . 1095

$\S 11$ Mitwirkung eines ausgeschlossenen Grundbuchbeamten bei einer Eintragung . . . . . . . . . . . . . . . . . . 1104

Anhang: Amtspflichtverletzung eines Grundbuchbeamten . . . . . 1110

$\S 12$ Einsicht des Grundbuchs, Abschriften . . . . . . . . . . . . . . . 1123 